\title{
Assessment of the impact of malaria on CD4+ T Cells and haemoglobin levels of HIV-malaria co-infected patients
}

\author{
Daniel Nii Aryee Tagoe and Joseph Boachie Jr \\ Department of Laboratory Technology (Medical Laboratory Division), University of Cape Coast, Ghana
}

\begin{abstract}
Introduction: The human immunodeficiency virus (HIV) and malaria destroy important cells required for proper immunological and haematological functioning of the body. This research therefore aimed to assess the effect of malaria on CD4+ and haemoglobin (Hb) levels of HIV-malaria co-infected patients.

Methodology: The study was performed by sampling 220 adult HIV patients on highly active anti retroviral therapy (HAART) who routinely visited the Tema General Hospital in Ghana. Blood samples were obtained for both blood film microscopy identification of malaria parasites and analysis using rapid diagnostic test kits. A BD Facscount Analyzer was used in the quantification of CD4+ levels.

Results: Of the 220 patients sampled, 34 (15.5\%) were HIV-malaria co-infected, all of whom (34; 100\%) had CD4+ counts below the normal range, while $23(12.9 \%)$ of the HIV mono-infected patients had normal CD4+ counts. Almost all HIV-malaria co-infected patients (33; 97.1\%) had low Hb levels, whereas 79 (42.5\%) of the HIV mono-infected patients had normal Hb. Malaria infection strongly correlated positively and significantly with both low $\mathrm{CD} 4+$ count $(\chi 2=0.828, P=0.003)$ and $\mathrm{Hb}(\chi 2=0.817, P=0.004)$ levels.

Conclusion: Malaria co-infection with HIV decreases CD4+ T cells and Hb levels in patients. It is therefore recommended that HIV patients in malaria endemic areas should adhere to malaria preventive measures.
\end{abstract}

Key words: CD4+ T cells; Hb levels; HIV-malaria co-infection; highly active anti retroviral therapy (HAART)

J Infect Dev Ctries 2012; 6(9):660-663.

(Received 14 June 2011 - Accepted 16 September 2011)

Copyright (C) 2012 Tagoe and Boachie Jr. This is an open-access article distributed under the Creative Commons Attribution License, which permits unrestricted use, distribution, and reproduction in any medium, provided the original work is properly cited.

\section{Introduction}

Malaria and HIV-1 are two of the most common infections in sub-Saharan Africa and, to a lesser extent, in other developing countries. It is estimated that 38 million Africans are infected with HIV-1 [1], whereas 300 million to 500 million suffer from malaria each year [2]. Given the overlap of their geographic distribution and resultant rates of coinfection, interactions between the two diseases pose major public health problems. Together they accounted for over three million deaths in 2007 and millions more are adversely affected each year [3]. Quantitatively, the mean parasite density has been reported to be 12-fold higher in HIV-positive compared with HIV-negative patients [4]. Among HIV-positive persons, parasitemia is more common, lower CD4+ counts are associated with higher parasite densities, and clinical malaria is more common [5]. Clear evidence indicates an interaction between HIV-1 and malaria in pregnancy, causing more peripheral and placental parasitemia, higher parasite densities, more clinical malaria, more anaemia, and increased risks of adverse birth outcomes [6]. HIV-infected women remain susceptible to the effects of malaria whether or not they are pregnant. A study into the effects of malaria on the viral load in HIV patients noticed a significantly higher HIV-proviral load in patients with malaria than those without, and this remained higher for at least four weeks after treatment [7]. This increase in HIV load could lead to a decrease in $\mathrm{CD} 4+$ that suggests malaria causes faster progression of HIV infection. Agbede et al. [8] observed a significant decrease in CD4+ count of patients infected with malaria attending the highly active antiretroviral therapy (HAART) clinic of the University of Ilorin Teaching Hospital, Ilorin, Nigeria. A computer simulation modelling study estimated that HIV would increase the incidence of clinical malaria and malaria deaths across the continent by more than 5\% [9]. Malaria is the single most important cause of morbidity and mortality in Ghana, especially in children under five years of age, pregnant women, and the poor [10]. In Ghana, 
malaria accounts for $31.1 \%$ of all outpatient illnesses, $30.3 \%$ of all admissions, and $30.3 \%$ of deaths in children younger than five years old [11].

High prevalence of malaria is reported in several communities in Tema and other neighbouring towns, and HIV patients who live in these communities are at a high risk of becoming co-infected with malaria. Thus the objective of this study was to determine the effect of malaria on CD4+ and Hb levels of HIVinfected patients.

\section{Methodology}

Study area and design

The study was conducted in the Tema Municipality of Ghana and specifically at Tema General Hospital, the main and largest hospital in the municipality, which is also an HIV-designated centre. The study was undertaken over a six-month period with bi-weekly purposive sampling of HIV-infected patients visiting the clinic routinely for medical review and estimation of their $\mathrm{CD} 4+$ count to ascertain their responsiveness to HAART.

\section{Ethical considerations}

The study was approved by the Tema General Hospital and the Department of Laboratory Technology, University of Cape Coast. Informed consent was obtained from all study participants. All procedures followed were in accordance with the ethical standards of the Ghanaian Ministry of Health as well as the Helsinki Declaration of 1975 [12].

\section{Patient selection criteria}

The study targeted medically diagnosed HIVpositive patients on HAART between the ages of 18 and 65 years who were scheduled to visit the hospital at regular intervals (every three months) for routine medical review as well as immune system evaluation of their responsiveness to treatment based on estimation of their CD4+ count. A total of $220 \mathrm{HIV}$ patients were sampled.

\section{Patient exclusion criteria}

Patients at the extremes of age, pregnant women, and those on chemotherapy were excluded from the study since they may naturally have a very weakened immune system. Additionally, patients not responding to HAART treatment from previous visits were also excluded.

\section{Laboratory investigations}

Study participants were enrolled after agreeing and signing an informed consent form. Blood was collected from participants into EDTA tubes. Thick and thin blood films were prepared and stained with Giemsa and observed under microscope to detect malarial parasites. Malaria positive samples were then confirmed with Rapid Diagnostic Test (RDT). Results were indicated as presence or absence of malaria parasite.

CD4+ lymphocyte counts were determined using the Becton Dickinson (BD) FACScount system (Becton, Dickinson and Company, CA, USA), while $\mathrm{Hb}$ was measured using a CELL-DYN 1800 automated haematological analyzer (Abbott Laboratories Diagnostics Division, Abbott Park, Il, USA).

Normal CD4+ count of $\geq 600$ cells/ $\mu \mathrm{L}$ and normal $\mathrm{Hb}$ values were $12-16 \mathrm{~g} / \mathrm{dl}$ for females and $13-$ $18 \mathrm{~g} / \mathrm{dl}$ for males according to the Ghana Health Service Guidelines, Ministry of Health, Ghana [13].

\section{Data analysis}

Data was analysed using SPSS 16.0 software (IBM, Chicago, Il, USA). Descriptive analysis was performed while Pearson's correlation was used to determine coefficients as well as double-tailed paired means comparison. $P \leq 0.05$ was considered significant and $P \geq 0.05$ not significant.

\section{Results}

Of the 220 patients sampled, 161 (73.2\%) were adult females and 59 (26.8\%) were adult males. The majority $(186 ; 84.5 \%)$ had HIV infection only while $34(15.5 \%)$ were HIV-P. falciparum malaria coinfected. None of the co-infected patients had a normal CD4 count ( $\geq 600$ ) compared to $24(12.9 \%)$ patients with HIV mono-infection. Only one $(2.9 \%)$ co-infected patient had normal $\mathrm{Hb}$, whereas 79 $(42.5 \%)$ of the HIV mono-infected patients had normal $\mathrm{Hb}$. None of the HIV mono-infected patients had severe anaemia compared with $6(18.2 \%)$ of the HIV-malaria co-infected patients (Table 1).

\section{Discussion}

Results from the study revealed that out of the 220 patients sampled, 34 (15.5\%) were co-infected with HIV and $P$. falciparum malaria. This concurs with works by Kublin et al. [14] who recorded 77 $(21 \%)$ cases of malaria infection in $367 \mathrm{HIV}$ patients in Malawi's Thyolo District. We also observed that 
Table 1. Laboratory parameters in HIV and HIV- malaria co-infection

\begin{tabular}{lcc}
\hline & HIV Mono-Infection (\%) & Category \\
Parameter & $186(84.5)$ & HIV-Malaria Co-infection (\%) \\
\hline Frequency & $24(12.9)$ & $34(15.5)$ \\
Normal CD4 Count $(>600)$ & $162(87.1)$ & $0(0)$ \\
CD4 Below Normal $(<600)$ & $114(61.3)$ & $34(100)$ \\
Slightly lowered immunity & & $3(8.8)$ \\
(CD4 200-600) & $72(38.7)$ & $31(91.2)$ \\
Very Weakened Immunity & & \\
(CD4 $<200)$ & $79(42.5)$ & $1(2.9)$ \\
Normal Hb levels $(12-18) \mathrm{g} / \mathrm{dl}$ & $107(57.5)$ & $33(97.1)$ \\
Anaemic & $107(100)$ & $27(81.8)$ \\
Moderate Anaemia $(7-12) \mathrm{g} / \mathrm{dl}$ & $0(0)$ & $6(18.2)$ \\
Severe Anaemia $(<7) \mathrm{g} / \mathrm{dl}$ & & \\
\hline
\end{tabular}

all $34(100 \%)$ patients who were co-infected with malaria had CD4 counts lower than the normal CD4 reference range $(\geq 600)$, implying that they all had lowered immunity. Additionally, a significant number $(91.2 \%)$ had very weakened immunity (CD4 $<200$ ) compared with $38.7 \%$ in HIV mono-infected patients. $P$. falciparum has been shown to stimulate HIV-1 replication through the production of cytokines (interleukin-6 and tumor necrosis factoralpha) by activated lymphocytes [15-16]. An important study from Malawi showed that HIV-1 plasma viral loads were significantly higher in patients with malaria infection than in those without, and these levels remained higher for up to 10 weeks after treatment [14], suggesting that malaria may speed the progression of HIV disease. These results agree with those observed in a study from Uganda that showed increased CD4 cell decline associated with episodes of malaria despite prompt treatment [17]. High HIV viral loads lead to a greater destruction of CD4 cells, resulting in lower immunity and a poor response to HIV treatments. Pearson correlation analysis of HIV-malaria co-infected patients and those with lowered CD4 count was strongly positive and significantly correlated $(\chi 2=$ $0.828, P=0.003)$. This is confirmed by research findings which indicate that in sub-Saharan Africa, with an HIV prevalence of $8 \%$, adult malaria secondary to HIV is $4 \%$ parasitaemia and $5 \%$ clinical malaria. In southern Africa, where the HIV prevalence is $30 \%$, these rates increase to $20 \%$ and $30 \%$ [18].

The result of the haematological changes $(\mathrm{Hb}$ levels) in the patients showed that just one $(2.9 \%)$ HIV-malaria co-infected patient had normal $\mathrm{Hb}$ values, whereas $79(42.5 \%)$ of the HIV monoinfected patients had normal $\mathrm{Hb}$.
Additionally, of the anaemic patients, none of the HIV mono-infected patients were severely anaemic compared with six $(18.2 \%)$ of the HIV-malaria coinfected patients. Clear evidence indicates an interaction between HIV-1 and malaria in pregnancy, causing more peripheral and placental parasitemia, higher parasite densities, more clinical malaria, more anaemia, and increased risks of adverse birth outcomes [6]. It has been observed that HIV-infected people in areas of malaria transmission have more frequent episodes of symptomatic parasitaemia and higher parasitaemias than those without HIV [19]. Increased parasitaemia leads to greater destruction of red blood cells causing anaemia in infected patients due to haemolysis (destruction of the red blood cells). A strong positive and significant association was observed $(\chi 2=0.817, P=0.004)$ between malariainfected HIV patients and low $\mathrm{Hb}$.

This study demonstrates that malaria infection in HIV leads to further reduction in immunological and haematological indices required for patients to manage the disease and stay healthy. Thus measures should be put in place to prevent or treat as early as possible any co-infection in HIV patients to ensure that all HIV patients on therapy will respond adequately to have a boosted immune system and high $\mathrm{Hb}$ levels.

\section{Acknowledgment}

The authors thank all the HIV patients who agreed to be part of the study, as well as the management and staff of Tema General Hospital.

\section{References}

1. UNAIDS (Joint United Nations Programme on HIV/AIDS) (December, 2004) AIDS epidemic update: UNAIDS, Geneva, 2004. 
2. World Health Organization. The roll back malaria partnership. Available

at: http://rbm.who.int/publications.html. Accessed 5 June 2011.

3. World Health Organization. World Health Report. Introduction and Overview (2008) http://www.who.int/whr/2008/overview/en/index.html. Accessed June 2011.

4. Birku Y, Mekonnen E, Bjorkman A, Wolday D (2002) Delayed clearance of Plasmodium falciparum in patients with human immunodeficiency virus co-infection treated with artemisinin. Ethiop Med J 40 Suppl 1: 17-26.

5. Whitworth J, Morgan D, Quigley M, Smith A, Mayanja B, Eotu H, Omoding N, Okongo M, Malamba S, Ojwiya A (2000) Effect of HIV-1 and increasing immunosuppression on malaria parasitaemia and clinical episodes in adults in rural Uganda: a cohort study. Lancet 356: 1051-1056.

6. ter Kuile FO, Parise ME, Verhoeff FH, Udhayakumar V, Newman RD, van Eijk AM, Rogerson SJ, Steketee RW (2004) The burden of co-infection with human immunodeficiency virus type 1 and malaria in pregnant women in sub-saharan Africa. Am J Trop Med Hyg 71: 4154.

7. Hoffman IF, Jere CS, Taylor TE, Munthali P, Dyer JR, Wirima JJ, Rogerson SJ, Kumwenda N, Eron JJ, Fiscus SA, Chakraborty H, Taha TE, Cohen MS, Molyneux ME (1999) The effect of Plasmodium falciparum malaria on HIV-1 RNA blood plasma concentration. AIDS 13: 87-94.

8. Agbede OO, Ajiboye TO, Olatunji M, Kolawole OM, Babatunde SA, Odeigha OL (2010) Evaluation of Cd4+ T Cells in HIV patients presenting with malaria at the University of Ilorin Teaching Hospital, Nigeria. EXCLI Journal 9: 58-66.

9. Korenromp EL, Williams BG, de Vlas SJ, Gouws E, Gilks CF, Ghys PD, Nahlen BL (2005) Malaria attributable to the HIV-1 epidemic, sub-Saharan Africa. Emerg Infect Dis 11: 1410-1419.

10. Ministry of Health (2009) "Revised Anti-malaria Drug Policy for Ghana, Final Draft" Accessed 5June 2011.

11. Ghana Malaria Action Alert (GMAA) (2010) Making malaria medicines available and affordable. 12: 1-4.
12. Nuffield Council on Biothethics (2002) In the ethics of research related to healthcare in developing countries. Nuffield Council on Bioethics 59.

13. National HIV/AIDS/ STI Control Programme (2010) Guidelines to antiretroviral therapy in Ghana. Ministry of Health / Ghana Health Service, 17-22.

14. Kublin JG, Patnaik P, Jere CS, Miller WC, Hoffman IF, Chimbiya N, Pendame R, Taylor TE, Molyneux ME (2005) Effect of Plasmodium falciparum malaria on concentration of HIV-1-RNA in the blood of adults in rural Malawi: a prospective cohort study. Lancet 365: 233-240.

15. Froebel K, Howard W, Schafer JR, Howie F, Whitworth J, Kaleebu P, Brown AL, Riley E. (2004) Activation by malaria antigens renders mononuclear cells susceptible to HIV infection and re-activates replication of endogenous HIV in cells from HIV-infected adults. Parasite Immunol 26: 213-217.

16. Xiao L, Owen SM, Rudolph DL, Lal RB, Lal AA (1998) Plasmodium falciparum antigen-induced human immunodeficiency virus type 1 replication is mediated through induction of tumor necrosis factor-alpha. J Infect Dis 177: 437-445.

17. Mermin J, Lule JR, Ekwaru JP (2006) Association between malaria and CD4 cell count decline among persons with HIV. J Acquir Immune Defic Syndr 41: 129-130.

18. Whitworth JA and Hewitt KA (2005) Effect of malaria on HIV-1 progression and transmission. Lancet 365: 196-197.

19. Kamya MR, Gasasira AF, Yeka A, Bakyaita N, Nsobya SL, Francis D, Rosenthal PJ, Dorsey G, Havlir D (2006) Effect of HIV-1 infection on antimalarial treatment outcomes in Uganda: a population-based study. J Infect Dis 193: 9-15.

\section{Corresponding author}

Daniel Nii Aryee Tagoe

Clinical Microbiology and Immunology

University of Cape Coast

Ghana

Telephone/Fax: +233 (0) 244233340

Email: dnatagoe@gmail.com

Conflict of interests: No conflict of interests is declared. 